\title{
Exploration and Practice of Engineering Management Professionals Training Based on the Internet and BIM
}

\author{
Lihui Rong \\ Dianchi College of Yunnan University \\ Kunming, China
}

\begin{abstract}
In order to improve the quality of innovative personnel training in engineering management, this paper explores the talent training program, training mode, curriculum system, and gradually forms a new training program and curriculum system for engineering management. Through the introduction of the Internet, virtual simulation, big data, cloud computing and other new technologies, the traditional engineering management specialty was upgraded to create a new construction engineering information training platform. The results show that information technology and engineering education are deeply integrated, and the teaching methods of Engineering Education in the "Internet and BIM" environment are innovating to improve the efficiency and effectiveness of engineering education.
\end{abstract}

Keywords-talent training; BIM Technology; engineering management

\section{INTRODUCTION}

At present a big bottleneck that affects the development of information technology in the construction industry is that there is a serious shortage of application-oriented talents in the construction industry. The traditional talents trained in engineering management are seriously lack of theoretical knowledge and application ability of building informatization. Even if some schools set up some related courses sporadically, they are not systematic, especially for applied talents, they can not meet the requirements of rapid development of building informatization.

Building information technology based on BIM (Building Information Modeling) technology has become one of the main characteristics of the modernization of construction industry. The application of BIM technology can change the traditional concept of building management and lead the building information technology to a higher level. Its comprehensive application will greatly improve the integration of building management. If the application of CAD technology is regarded as the first change of architectural engineering design, the emergence of building digital information model technology will lead to the second change of construction industry. At present, China's construction industry is experiencing a baptism of BIM.

Fund projects: Scientific research fund project of Yunnan Provincial Department of Education."Research on the application of BIM Technology in the virtual construction of prefabricated buildings", No: 2018JS740

\section{THE NECESSITY OF BIM APPLIED TO TALENT TRAINING}

The traditional training model of engineering management talents is not conducive to the formation of the knowledge system of engineering management, because all the knowledge is independent of each other, which is not conducive to the students' organic integration of learning content and professional knowledge. A complete knowledge system of engineering management is conducive to the development of the core competitiveness of engineering management. The emergence and development of BIM technology can help students to connect and integrate their professional knowledge through BIM, which provides a better medium for the cultivation of engineering management professionals. BIM can help college engineering management students to establish a more complete knowledge system, and BIM is also a technology that engineering management students need to master to adapt to the recognition and demand of the construction market for BIM.

According to the needs of information development in the construction industry, colleges and universities have introduced new technologies such as Internet, virtual simulation, big data, cloud computing, etc. to cultivate new "skills + management" application-oriented talents who can adapt to the development of information technology in the construction industry, have professional skills in basic engineering, and master the concept and means of information management. It is not only the need of social and economic development, but also conducive to solving the employment problem of students[1]. As a leading country in BIM Technology, the United States has carried out many explorations in the academic community. BIM course has been accepted and determined as the core part of several important undergraduate engineering management courses in the United States. Stanford University, Carnegie Mellon University, Pennsylvania State University, Arizona State University, Auburn University, Caltech, University of Maryland and Georgia Institute of technology have offered BIM related courses[2]. Central China University of science and technology, Guangzhou University and Wuhan University have set up corresponding BIM education courses[3].

For college students majoring in engineering management, in order to meet the needs of the transformation of the construction industry to high-end service industry in the future, they should not only pay attention to the construction of BIM 
basic courses[4], BIM theory and practice, BIM software and modeling, but also pay attention to introducing BIM into professional courses such as architectural design, engineering supervision, engineering valuation, engineering project management, real estate development and operation.

\section{MAIN IDEAS OF PERSONNEL TRAINING}

In terms of training mode, we should actively strive for various social resources[5], promote school enterprise collaborative education, and form a situation of complementary advantages, $\mathrm{CO}$ creation of projects, sharing of achievements, and win-win interests. Through the project construction, the existing engineering management specialty will be upgraded. For local colleges and universities, the new type of "skill + management" applied talents will be trained to adapt to the information development of the construction industry and master the information management concept and means. Basic engineering professional skills provide demonstration and reference for the promotion and transformation of the whole civil engineering professional group[6].

\section{A. The main ideas of personal training}

According to the proposed objectives and the problems to be solved, this paper strives to promote the deep integration of the knowledge, ability and quality requirements of information technology and civil engineering specialty, and explore the implementation path of the transformation and upgrading of engineering specialty.

On the basis of full investigation, this paper studies and analyzes the new requirements of the development of information technology in the construction industry for the training of traditional engineering management professionals. The goal is to cultivate new "skills + management" application talents who can adapt to the development of construction industry informatization, have basic engineering professional skills, and master the concept and means of informatization management. The core is to form a professional training program, build a curriculum system, explore the training mode of school enterprise collaborative education and informationbased teaching means of engineering education. Based on the BIM training center jointly built by Dianchi College of Yunnan University and Yunnan branch of China Academy of building science and Technology Co., Ltd., and taking the reform of engineering management major as the object, this paper explores and practices the transformation and upgrading of the major.

The goal of the project research is to explore the ways and means of traditional engineering information and digital teaching reform on the basis of "information development of construction industry" and "students' engineering ability". In the research process, the first is to pay attention to demonstration: multi-channel and multi-way research on the teaching status of civil engineering specialty and the needs of enterprise talents, and collect relevant information. This paper focuses on the evidence collection, data collection, investigation and interview of the talent training mode of relevant majors and industries in Colleges and universities at home and abroad, and makes a classification, sorting and in- depth analysis of these data. Second, we should pay attention to comprehensive integration, that is, we should conduct in-depth research from all levels, all angles and all sides, absorb the strengths of each family, and combine with our own reality to form a systematic, effective professional teaching system that is consistent with the training orientation of applicationoriented talents.

On the basis of full investigation, the whole project is divided into six sub projects, which are in charge of each other, supported each other, United and completed together.

\section{B. Integration of BIM and curriculum system}

In order to improve students' ability of applying BIM skills, BIM courses are added by combining new courses with embedded courses. Combined with practice curriculum system, for example, BIM field layout module is embedded in civil engineering construction; BIM model is embedded in engineering bidding and contract management to prepare bidding documents and simulate bidding process; BIM 5D module is embedded in engineering project management. The comprehensive practice level includes the course design of civil engineering construction, the course design of construction engineering quota and budget, the course design of engineering cost, the course design of installation engineering cost, graduation practice and graduation design. Practice teaching is an important part of training applicationoriented talents, so building BIM based practice curriculum is more practical, mainly reflected in the comprehensive practice level.

\section{PracticAl Application of TAlent Cultivation}

Relying on the platform of school enterprise cooperation, the college of construction engineering actively explores taking engineering projects as the carrier and accomplishing work tasks as the goal. Teachers and technical personnel of the school jointly form a professional teaching team to cooperate with each other in teaching. BIM pilot class is set up in level 13 engineering management major. The school and enterprise jointly formulate curriculum teaching plan, cross integrate multiple courses and implement teaching. The BIM pilot team has achieved gratifying results to assess the completion of work tasks. At present, it also cooperates with Kunming Lexun Digital Technology Co., Ltd. to explore the cultivation of engineering management professional upgraded students with the construction project information management as the main line. These pilot work will provide experience and reference for the exploration and practice of this project.

\section{A. Construction of talent training program and curriculum system}

In terms of the development trend of the construction industry informatization, based on the current situation of relevant professional training at home and abroad and the teaching method of Engineering Education under the "Internet +" environment, we study and adjust the training objectives and programs of engineering management professionals. On the premise of meeting the basic requirements of professional norms put forward by the national professional Steering 
future classroom. Smart classroom is a new type of education form and modern teaching means. Based on the Internet of things technology, it is a smart teaching system that integrates smart teaching, personnel attendance, environmental intelligent adjustment, video monitoring and remote control.

Colleges and universities should strengthen the construction of engineering professional teachers, actively introduce professional talents of BIM Technology, strengthen the training of teachers, actively organize the learning of BIM Technology, and improve the assessment system of teachers' BIM Technology teaching ability.

We should build a team of BIM Technology Education with excellent knowledge, strong ability and rich experience to ensure the quality of teaching. In addition, colleges and universities should strengthen the training of BIM teaching talents' practical experience through cooperation with off campus engineering enterprises and software development enterprises. Engineering teachers in Colleges and universities should enter into practical projects to exercise, enrich their experience in engineering construction and practical application of BIM Technology, and improve their practical ability ,so that it can become a professional BIM Technology teaching talent.

team cooperation, theory and practice. The integration of industry and education curriculum construction, curriculum content and project docking, teaching quality standards and professional standards are relatively connected.

We take BIM technology application as the main line and highlight the professional service orientation and field, get through the information flow between civil engineering disciplines.

\section{Innovation of teaching methods centering on engineering education information}

The construction of new engineering should meet the challenge of new technology. Professional reports predict that higher education will develop in the direction of innovation, cross-border, opening and interaction in the future. In order to cultivate the talents needed in the 21st century, universities need to promote digital education, adopt new technologies such as artificial intelligence, adaptive learning and mixed reality, and improve the teaching level.

The emerging technologies of engineering education informatization include MOOC, hybrid teaching, flipped classroom, virtual reality, augmented reality, 3D technology, artificial intelligence, micro class platform, BIM technology, etc.

Super star Fanya network teaching platform (mobile super star learning APP) formed by mobile Internet provides network teaching platform, network teaching resources, network teaching videos, etc., optimizes teaching content, improves teaching methods and teaching means, and adds new assessment methods, such as reading, visiting times, discussing and participating topics of web courseware and Usual tests, etc.

Smart classroom can optimize the presentation of teaching content, facilitate the acquisition of learning resources, promote the interactive development of classroom, and highly modern new classroom ", which is a form of digital classroom and

\section{The application of specific course teaching reform}

According to the new teaching methods and intelligent mobile teaching, the teacher team is applied to the corresponding courses. Such as CAD parametric design, using BIM Technology, micro class and mobile teaching tools, the teaching content, teaching methods, teaching methods and assessment methods of this course are reformed. For example, in civil engineering construction, virtual simulation technology, micro course and mobile teaching tools are used to reform the teaching content, teaching methods, teaching methods and assessment methods of this course. Form the "great transformation" of curriculum teaching mode, and integrate multi-disciplinary teaching resources, teachers apply for scientific research projects of teaching reform, and improve the ability of teaching and scientific research.

Taking students' ability to cut into engineering practice as the core, this paper explores a four-year continuous line, multilevel and multi module practical teaching system. We develop design and comprehensive experimental and practical training projects to let students experience the whole construction process from shallow to deep, from single to comprehensive, from simulation to innovation. We train students to gradually establish engineering awareness, innovation awareness, and strive to make students combine theoretical knowledge with practical application, experimental skills with practical operation application, and use cloud technology and virtualization technology to create a construction engineering information training platform, which integrates multidisciplinary and multi course knowledge, so as to effectively improve students' engineering quality and practical ability.

\section{CONCLUSION}

This paper starts from the personnel training plan, training mode, training means, training conditions and so on, and 
comprehensively upgrades the traditional engineering management specialty.

Based on the construction engineering Internet and BIM, a talent training program with interdisciplinary integration and meeting the needs of the development of information technology in the construction industry should be established.

We should explore the mechanism of school enterprise cooperative education, break down the system barriers and inherent discipline boundaries, build a management team with multiple participation and interdisciplinary integration, and build a team of teachers who work closely with enterprise technicians to teach together.

We should pay attention to the renewal of teaching methods, use cloud technology and virtualization technology, and build an information project training platform combining virtual $h$ reality. By exploring the teaching methods of Engineering Education in the information age, and integrating the knowledge of multiple specialties and courses, we have established a practical teaching system that is consistent with the training orientation of applied talents.

\section{REFERENCES}

[1] Jianping Zhang, Ding li, Jiarui Lin. “Application of BIM in engineering construction”[J]. Construction technology, 2012.(In Chinese)

[2] David W Cearley, Brian Burke, Samantha Searle, Mike J Walker.Top10 Strategic Technology Trends for 2018 [EB/OL]. https://www.gartner.com/doc/3811368?srcId=1-6595640781.

[3] Fang Wang, Zhiqiang Zhang. “Optimization and application of practical teaching platform for BIM integrated applied civil engineering specialty"[J]. Higher architectural education,2016, 5(1): 155-157.(In Chinese)

[4] Yufang Sun, Xia Xu. "Curriculum system construction of engineering management major in Applied Undergraduate Colleges"[J]. Education modernization, 2016 (38): 129-131.(In Chinese)

[5] Yilin Yin, Yige Liu. "Exploration and Research on the ability evaluation of Application-oriented Undergraduate Majors - taking engineering management as an example”[J]. Modern education technology, 2013,23 (11): 119-123 (In Chinese)

[6] Chunlin Wu, Qiong Tian, Zhongfeng Qin. "Research on the training mode of engineering management talents in Universities under the background of 'one belt and one road' construction" $[\mathrm{J}]$. Higher architectural education, 2019 (1). (In Chinese) 